\title{
Not Next to You: Peer Rejection, Student Characteristics and the \\ Moderating Effects of Classroom Composition
}

\author{
Simon Hjalmarsson* \\ Stockholm University \\ Peter Fallesen \\ Stockholm University \\ ROCKWOOL Foundation \\ Stephanie Plenty \\ Stockholm University \\ Institute for Futures Studies
}

* Corresponding author: Simon Hjalmarsson, SOFI, Stockholm University, SE-106 91

Stockholm, Sweden. Email: simon.hjalmarsson@sofi.su.se.

The authors thank Viveca Östberg, Martin Hällsten, Magnus Bygren, Carina Mood, Elizabeth

Thomson, Merlin Schaeffer, Anders Holm, and the Level-of-living group at the Swedish Institute for Social Research, Stockholm University for constructive comments. Previous versions presented at meetings for the RC28 and the PAA. The study received funding from the Swedish Research Council for Health, Working Life and Welfare (grants no. 2012-1741; 2016-07099; and 2017-00947). Additional funding from the ROCKWOOL Foundation gratefully acknowledged by Peter Fallesen. 


\begin{abstract}
Although sociodemographic characteristics such as immigrant background and low socioeconomic status have been found to increase the risk for peer rejection, it remains unclear whether rejection in school settings primarily occurs between different-characteristic peers or is also driven by samecharacteristic peers, nor whether these types of processes are moderated by classroom composition. Building on person-group dissimilarity theories, we address this gap in the literature using a large sample of 4,215 Swedish students (aged 14-15) in 201 eighth grade classes. Sociometric data provide information on received rejection nominations and rejection networks in school classes. Five characteristics are examined at the student- and classroom-levels: gender, immigration background, household income, parental education, and cognitive ability. Information on sociodemographic characteristics is drawn from linked survey and administrative population registers. A two-pronged empirical strategy is used, using both multilevel random effects models and Exponential Random Graph Models. We find that multiple characteristics are associated with peer rejection, and classroom composition moderates how these characteristics are associated with the extent to which students are rejected and reject classmates who are different to themselves.
\end{abstract}




\section{Introduction}

Peer rejection hurts-both figuratively and literally. Poor peer relations can seriously undermine students' school engagement and psychological well-being (Arseneault, Bowes, and Shakoor 2010; Buhs, Ladd, and Herald 2006; Eriksen, Nielsen, and Simonsen 2014; Nakamoto and Schwartz 2010; Wolke and Lereya 2015). While youth with certain sociodemographic characteristics are at greater risk of rejection at school than others (e.g., Hjalmarsson 2018; Knaappila et al. 2018; Plenty and Jonsson 2017; Veenstra et al. 2010), it remains unclear whether rejection in school settings primarily occurs between different characteristic peers or is also driven by same characteristic peers. In addition, knowledge is lacking on whether such processes of rejection are moderated by classroom composition.

Social network studies show that friendships often segregate along sociodemographic lines (e.g., Smith et al. 2016), while person-group dissimilarity studies show that adolescents are more likely to be rejected by peers when they noticeably differ from the context-specific group norms (Mikami, Lerner, and Lun 2010; Wright, Giammarino, and Parad 1986). Although these two tendencies are likely to contribute to the marginalization of students belonging to minority or lowstatus social groups, it is unclear how student characteristics and classroom composition jointly influence how students reject each other, nor which characteristics are key drivers of rejection.

Peer rejection is commonly addressed in more explicit terms such as bully victimization or being disliked. However, peer rejection generally involves devaluing a relationship with another individual and a desire to increase one's physical and psychological distance to that individual (Leary 2015). This means that many studies overlook social dynamics that are more subtle but still harmful to inter-group relations and student well-being. In response, this study examines peer rejection in the classroom setting based on students' nominations of classmates they do not want to sit next to, capturing students' avoidance of or reluctance to affiliate with a classmate. 
We use a large sample of Swedish students $(n=4,215)$ from 201 classrooms to study how multiple sociodemographic characteristics at the student and classroom-levels shape peer rejection. Using a two-pronged analytical approach applying multilevel OLS regression as well as Exponential Random Graph Models (ERGMs), we comprehensively study how interactions between student characteristics and classroom composition influence which students are rejected and the extent to which students reject classmates who are different to themselves.

\section{The Contextual and Interpersonal Processes Underlying Peer Rejection}

Peer relationships are inevitably embedded in the social contexts in which they develop. Socialecological models posit that the determinants of rejection depend on complex interactions between individuals and their social environment (Hong and Espelage 2012). Tests of person-group dissimilarity theory extend this perspective by showing that students with behaviors or personalities that deviate from others in some discernible way are at risk of lower acceptance, as well as more bullying and aggression from peers (Boele et al. 2017; Boivin, Dodge, and Coie 1995; Chang 2004; Sentse et al. 2007; Stormshak et al. 1999; Wright, Giammarino, and Parad 1986). In relation to sociodemographic factors, students who have few classmates with similar ethnic and socioeconomic characteristics have been found to experience greater loneliness, less acceptance, and lower sense of belonging among peers than those with a larger proportion of similar classmates (Benner and Wang 2014; Crosnoe 2009; Madsen et al. 2016).

Power Imbalance Theory argues that peer rejection is more likely in contexts where one's group constitutes the numerical minority because of the group's reduced social power in such circumstances (Graham 2006). Although this theory was developed to address inter-ethnic relations, the rationale is arguably applicable to other sociodemographic characteristics - a student's social power is likely to be weaker in classrooms where their characteristic is less common. For students belonging to groups considered low or minority status at the societal level 
(such as females, immigrants, or low SES), classrooms with little sociodemographic representation may exacerbate their social vulnerability. However, classrooms with higher sociodemographic representation could shift the balance of power to their advantage, thereby reducing their likelihood of rejection.

In summary, the literature on person-context interactions suggests that youth's experiences of rejection vary according to how their characteristics match the dominant characteristics in the specific context that peer relations unfold. Rejection increases when a student deviates from the group norm. Thus, by creating local norms and majorities that may differ from the norms and majorities of society at large, we could expect classroom composition to moderate the associations between an individual's sociodemographic characteristics and the extent to which they are rejected. Although this perspective helps us understand who are likely to be more rejected in different classrooms, it does not address the source of rejections nor how the social rules governing rejection may depend on local classroom majorities and average characteristics. To further understand classroom processes of peer rejection, we incorporate a network perspective that allows us to consider interpersonal preferences within the classroom.

Which psychological processes then govern how students reject each other? Social identity theory suggests that individuals intrinsically categorize themselves and others into groups according to a range of characteristics, such as gender, ethnicity, social background. Individuals hold multiple identities according to these categories, which shape self-concept, preferences, and behaviors (Tajfel 1982; Tajfel and Turner 1979). Due to an assumed sense of familiarity and in order to boost self-esteem and maintain a positive view of one's affiliated groups, there is a tendency to favor others perceived as belonging to the "ingroup" and to distance oneself from those considered as “outgroup" members (e.g., Boda and Neray 2015). Thus, interpersonal preferences are guided by one's social identity and intergroup considerations. Rejecting others with 
characteristics distinct to oneself is known as outgroup derogation, which can be understood as rejection heterophily in social network terms. Although extreme forms of outgroup derogation may involve hostility, it also involves more moderate acts such as avoidance behaviors or making negative judgments about others. Drawing on social identity theory, we could expect students to reject classmates with different (perceived) sociodemographic characteristics to themselves more than they reject classmates who share the same characteristics.

Although individuals tend to reject others who belong to different social groups, this tendency is likely to vary depending on the sociodemographic characteristics that are typical in a given context. Thus, a question arises on whether classroom composition moderates the tendency for students to reject peers because of dissimilarity (i.e., outgroup derogation). Are sociodemographically marginalized students rejected primarily by different-characteristic peers, or do same-characteristic peers also reject them? It is probable that sociodemographically marginalized students experience greater rejection simply due to the larger presence of different-characteristic classmates that can nominate them. However, it is also possible that they experience greater rejection because persondissimilarity processes lead the majority group's outgroup derogation to strengthen. A third scenario is also feasible, where students belonging to a situational minority group might reject their same-characteristic peers to align themselves more closely with the more accepted or powerful majority group.

Despite the risks that peer rejection presents for adolescents' school adjustment and wellbeing, the social network literature on negative ties remains scarce, with little attention paid to how various sociodemographic characteristics may act as determinants of rejection, nor the extent to which social contexts influence these associations. The few studies that do exist center on ethnicity (e.g., Boda and Neray 2015). The peer relations literature also points to lower socioeconomic status and lower academic ability as likely risk factors for rejection, while gender is a key stratifier of 
friendship preferences (e.g., Gifford-Smith and Brownell 2003). Consequently, to better understand the nature of rejection, this study asks how a range of key characteristics are linked with peer rejection in terms of sociometric nominations and provides an additional contribution by studying this as social networks.

\section{The Current Study}

For most adolescents, the classroom setting serves as a core social arena by providing a foundation for the formation of social relationships among same-age peers (Neckerman 1996). However, for many students, these social interactions involve being rejected by classmates. This study considers how a range of student sociodemographic characteristics may interact with classroom composition in shaping peer rejection. We ask two distinct but related questions. First, what is the moderating effect of classroom composition on being the target of peer rejections? Second, how does classroom composition moderate the structure of peer rejections — that is, the likelihood of certain students rejecting certain others. Although peer rejection can be conceptualized in many ways, we operationalize rejection as the preference for not wanting to sit next to a classmate. This permits a broad perspective, encompassing passive acts of avoidance to potentially overt hostile relations. We address how student characteristics and classroom composition of these characteristics affect who is rejected, as well as which students reject whom, by testing the influence of five characteristics: gender, immigration background, parental income, parental education, and cognitive ability.

In line with person-group dissimilarity theory (e.g., Wright, Giammarino, and Parad 1986) and power imbalance theory (Graham 2006), we expect that students who differ from their classmates on a key characteristic will receive more rejection nominations in classes where this characteristic is less prevalent (H1). In line with social identity theory (Tajfel 1982; Tajfel and Turner 1979), we hypothesize that adolescents will receive more rejection nominations from 
different-characteristic classmates than same-characteristic classmates, indicative of outgroup derogation $(\mathrm{H} 2)$. However, based on person-group dissimilarity theory and power imbalance theory, we expect outgroup derogation to be stronger in classes where the different-characteristic classmates are less prevalent (H3).

\section{Data and Methods}

Data come from the Children of Immigrants Longitudinal Study in Four European Countries (CILS4EU), a project designed to examine the structural, cultural, and social integration of youth in Europe (Kalter et al. 2014). The current study uses Swedish data from the first wave (winter 2010 and spring 2011) when participants were in the eighth grade (approximately 14-15 years of age). Statistics Sweden (the Swedish national statistics agency) collected data in schools across Sweden using a three-step stratified sampling approach. Schools were randomly selected within four strata based on the proportion of children of immigrant background within the school, oversampling schools with a higher proportion of students of immigrant background. Two classes within each school were then randomly sampled and then all students in the selected classes were invited to participate (CILS4EU 2016). Students completed sociometric nominations, a questionnaire, and ability tests during normal lesson time. Data collection was approved by the Regional Ethics Committee of Stockholm (approval reference number 2010/1557-31/5), and students and their parents provided informed consent.

The base sample consisted of 5,699 students, in 251 classes, and 129 schools. We omit the following cases: a) students absent from class during data collection $(n=674)$; b) data from 26 students (including the sociometric nominations they made) deemed to have provided unreliable or implausible responses; c) 38 classes (616 students) where less than $70 \%$ of students responded to the peer rejection item, following recommendations to ensure valid sociometric data (e.g., Cillessen and Marks 2011); d) 13 classes with less than 12 participating students to improve the validity of 
the rejection measure. The analytical sample thus consists of 4,215 students in 201 classrooms and 119 schools ( $74 \%$ of students from the base sample).

\section{Measuring Peer Rejection}

Students were presented with a roster listing the names of all classmates (including absent students) and asked to nominate up to five students that they did not want to sit next to. Participants could not nominate themselves nor nominate the same classmate multiple times. These nominations allowed us to generate directed rejection networks for all classrooms and calculate a rejection score for each student.

The rejection score represents the number of rejection nominations each student received (the in-degree), standardized by classroom size. Thus, scores range between values of zero and one. In Equation 1 below $\operatorname{deg}^{-}(v)$ is the number of rejection nominations a student received, and $n-1$ is the highest number of possible rejection nominations a student can receive.

$$
\text { rejection }=\frac{\operatorname{deg}^{-}(v)}{n-1}
$$

\section{Student Characteristics}

We included four sociodemographic characteristics: gender, immigration background, household income, and parental education. Information on gender came from survey data (males $=0$, females =1). Immigration background was based on student reports and administrative register data on parental country of origin. Students with one Swedish born parent are classified as of Swedish origin (1), while students with both parents born outside of Sweden are classified as of immigrant background (0). ${ }^{1}$ Information on household income and parental education came from administrative register data. Household income reflected the total post-tax income from labor, capital, and social benefits of custodial parents in the year 2010. In cases where parents lived in 
separate households, we used the mean of the two households. Information on parental education was recoded to represent years of education for the parent with the longest education.

In addition to the sociodemographic characteristics, we included a measure of cognitive ability. This was to control for academic ability, which could influence how attractive a student is to sit next to. Cognitive ability was assessed using the "Culture Fair Intelligence Test", a timed pattern recognition test (CFT20R; see Weiß 2006). The test score has a possible range between 0 and 27. Table 1 presents the descriptive statistics of our explanatory variables.

\section{[TABLE 1 ABOUT HERE]}

\section{Classroom Characteristics}

We generated five classroom-level variables by calculating the aggregated means of each of the four student sociodemographic characteristics and cognitive ability at the classroom-level. For gender and immigration background, these represented the share of female students and Swedish origin students in each class, respectively. For household income and parental education, these represented the class mean household income and mean number of years of education for students' most highly educated parent, respectively. A measure of cognitive ability was also generated based on the mean cognitive ability of students in each class. Table 2 presents the proportion of variance for each of the characteristics that is attributable to between classroom differences by using unconditional interclass correlations. Immigration background shows the highest ICC, which is partly due to the sampling strategy that oversampled immigrant-dense classrooms. Household income had the next-highest ICC, where $21 \%$ of the total variation occurs at the classroom-level, likely reflecting differences in neighborhood affluence between schools. For parental education, $15 \%$ of the variation occurs at the classroom-level, again indicating some clustering. For cognitive ability, $13 \%$ of the variation is accounted for at the classroom-level. For gender and peer rejection, 
the ICCs are close to zero and bordering significance at the conventional 5\% level, indicating that almost all variation occurs within classrooms. ${ }^{2}$ The ICC for gender is expected, given that schools are likely to aim for gender-balanced classrooms. For peer rejection, it indicates that the average level does not seem to systematically vary across classrooms. However, this does not mean that the distribution of peer rejection is similar across classrooms, merely that the classroom-level of rejection is similar across classrooms.

[TABLE 2 ABOUT HERE]

\section{Analytical Strategy}

\section{Analysis of Who Receives Peer Rejection Nominations: Multilevel Random Effects Regression}

In the first part of our analysis, we examine whether the classroom composition of a given characteristic moderates the degree to which a student with that characteristic is rejected (e.g., whether girls receive fewer rejections when the share of girls in the classroom is larger).

We estimate the following model for individuals $i$ nested in classrooms $c$ :

$$
\text { rejection }_{i c}=\beta_{0}+\gamma_{c}+\boldsymbol{X}_{i c} \boldsymbol{\beta}+\overline{\boldsymbol{X}}_{\boldsymbol{c}} \boldsymbol{\gamma}+\boldsymbol{V}_{\boldsymbol{i c}} \boldsymbol{\delta}+\alpha_{c}+\epsilon_{i c}, \quad \boldsymbol{V}_{\boldsymbol{i c}}=\sum_{x} \delta_{x} X_{i c} * \overline{\boldsymbol{X}}_{\boldsymbol{c}}
$$

rejection $_{i c}$ is the peer rejection score. $\beta_{0}$ is the constant term, $\gamma_{c}$ is the classroom-level random intercept. $\boldsymbol{X}_{\boldsymbol{i c}}$ is a matrix of individual-level characteristics. $\overline{\boldsymbol{X}}_{\boldsymbol{c}}$ is the classroom-level average characteristics. $\boldsymbol{V}_{\boldsymbol{i c}}$ is the interaction between individual- and classroom-level characteristics, representing the moderating influence of classroom composition on individual characteristics. $\alpha_{c}$ is the classroom-level error term. $\epsilon_{i c}$ is the individual specific error term. The model in Equation 2 allows us to examine, for example, how the share of students of Swedish origin in a classroom moderates the impact of Swedish origin on being rejected. We use a multilevel random effects model, with a random intercept to capture variation in $\alpha_{c}$. For ease of interpretation, 
household income, parental education, and cognitive ability are grand mean centered. To obtain correct standard errors while including cross-level interactions, we use robust clustered standard errors at the classroom-level.

\section{Analysis of Who Rejects Whom: ERGM Specification and Metaregression}

The second part of the analysis examines the structure of classroom rejection networks, allowing us to examine outgroup derogation (the tendency to reject classmates that differ to oneself) and whether this is moderated by classroom composition. Following Snijders and Baervaldt (2003), we specify a directed Exponential Random Graph Model (ERGM) and use this to examine the structure of rejections at the classroom-level. ${ }^{3}$ We then use metaregression to estimate average parameters across classroom networks and examine whether parameter values differ systematically between classrooms (cf. Smith et al. 2016).

ERGMs are statistical models for examining the structure of ties in social networks. In an ERGM framework, networks are composed of local patterns of network ties (termed configurations), corresponding to assumptions about how the propensity for certain ties depend on the presence of other ties in the network. An ERGM is specified through the inclusion of configurations, and parameters are estimated by applying (pseudo) maximum likelihood models to an observed network.

Our ERGM specification includes student (actor) characteristics, between-student characteristics, as well as network structure characteristics (see Supplementary material, Appendix A for details). The model allows us to examine if students with certain characteristics are more likely than their counterparts to reject and be rejected by classmates. Our main interest lies in examining interactions between characteristics of those who reject and characteristics of those who are rejected to identify the extent of outgroup derogation based on each characteristic. For gender 
and immigration background, these interactions effectively represent heterophily (rejecting different-characteristic peers) if the parameters are negative, and homophily (rejecting samecharacteristic peers) if the parameters are positive. For household income, parental education, and cognitive test scores, absolute difference terms are used, with positive parameters indicating heterophily (that students are increasingly likely to reject someone when the difference between them is larger). Further, we calculate conditional odds ratios to facilitate the interpretation of significant interaction terms (cf. Boda and Neray 2015). See Table A1 in Supplementary material for the full list of student characteristic parameters.

To accurately make inferences about the role of student characteristics in shaping peer rejection in the classroom, we must control for aspects of the network structure that reflect social rules governing rejection independently of student characteristics. Our specification of the network structure was informed by theory (Lusher and Robins 2013; Robins, Pattison, and Wang 2009) and by previous studies of negative tie networks (e.g., Boda and Neray 2015; Harrigan and Yap 2017; Huitsing et al. 2012; Wittek, Kroneberg, and Lämmermann 2020). Our specification also reflects an iterative process (on a sub-sample of networks), whereby we removed structural network parameters impeding model convergence and used goodness of fit statistics to inform decisions to include additional structural parameters. Because these network parameters are not our main focus, we present the full list of structural parameters and their interpretation in Appendix A (in the Supplementary material). Further, because each student can nominate a maximum of five classmates, we restrict the ERGM to a maximum of five outgoing rejection nominations per student. We restrict the maximum number received rejections for each student to $n-1$, where $n$ is the number of students in the classroom.

The ERGM model produces a unique set of estimates for each classroom. Metaregression was used to summarize the network model parameter estimates across classrooms and to examine 
whether the estimates differ systematically between classrooms. We do this by first calculating the metaregression equivalent of within class-correlation, $I^{2}$, which captures the share of variation in the estimate that is attributable to variation between classroom networks. We then include classroom-level characteristics as right-hand side variables in the metaregression to examine if the ERGM parameters are moderated by classroom characteristics (Smith et al. 2016).

\section{Results}

\section{Descriptive Results}

We first present the distribution of received rejection nominations. Because classrooms differed in size, providing a sample histogram of the number of received rejection nominations will be imprecise. Similarly, showing the normalized distribution makes interpreting the number of nominations difficult. Instead, we multiply the (normalized) peer rejection score with the average classroom size (comprising 21 students) in the analytical sample. Figure 1 shows the distribution of received rejection nominations scaled by the average sized classroom in our data. Almost $40 \%$ of students in the average classroom received no rejection nominations, with the proportion of students decreasing as the number of received rejection nominations increased. Thus, large variation in the number of rejection nominations that students received exists within classrooms.

[FIGURE 1 HERE]

\section{Results from Multilevel Random Effect Models: Who Receives Peer Rejection Nominations?}

We now turn to the first part of our analysis on the moderating effects of classroom-level characteristics on the number of rejection nominations a student receives. Table 3 presents the results from the multilevel random intercept model with students' rejection score as the dependent variable. Model 1 includes only individual-level characteristics, Model 2 in addition includes classroom-level characteristics, and Model 3 adds cross-level interactions. As the rejection score is 
bounded between zero and one, with higher values indicating more received rejection nominations, the estimates can be interpreted as percentage-point changes (divided by 100) in the extent of rejection intensity when a covariate increases with 1 .

\section{[TABLE 3 ABOUT HERE]}

Starting with Model 1, we see that girls, students of Swedish origin, with higher household income, and with higher cognitive ability all received significantly fewer rejection nominations than their counterparts did, but we do not find an association with parental education. On average, Swedish origin students were rejected by 1.6 percentage points fewer classmates than students of immigrant background and each 100,000 SEK increase in household income was associated with receiving 0.4 percentage points fewer rejection nominations.

In Model 2, we find that students in classes with a higher share of Swedish origin students had larger peer rejection scores, beyond the effects of individual-level characteristics. We also see that the coefficient for Swedish origin more than doubles in size when we account for classroomlevel variables. In other words, the individual-level association between Swedish origin and rejection was mediated by classroom characteristics, and when we account for the fact that Swedish origin students often attend school classes with a higher share of Swedish origin students (who also tended to have a higher level of rejection, all else equal), the individual-level association become stronger.

In Model 3, we observe significant interactions between the individual- and classroom-level characteristics for gender, immigration background, household income, and cognitive ability (immigration background and income are not significant at conventional levels, but are significant at the $10 \%$ level; $p=0.062$ and 0.072 , respectively). Figure 2 illustrates the interaction effects from Model 3. In classrooms with a lower share of girls (and thus higher share of boys), girls and boys 
received a similar number of nominations. But in classrooms with a higher share of girls, boys received more rejection nominations while girls received fewer nominations. Both students of immigrant background and students of Swedish origin received increasingly more rejection nominations in classrooms with a higher share of Swedish origin students, but as the share increased, the increase in received rejection nominations was stronger for immigrant background students than Swedish origin students. Household income followed a different pattern, as indicated by the positive cross-level interaction coefficient. Higher income was slightly more protective in classes with lower average income than in classes with higher income. For cognitive ability, students with lower cognitive ability received more rejection nominations in classrooms with higher average cognitive ability than in classrooms with lower average cognitive ability.

[FIGURE 2 HERE]

Thus, Hypothesis 1 was partially supported as students who differed from their classmates in terms of gender (particularly boys), cognitive ability, and having an immigrant background received more rejection nomination in classes where these characteristics were less common. However, both students of immigrant and Swedish origin received more rejection nominations in classes with a higher share of Swedish origin students. Nevertheless, the effect was larger for students with an immigrant background.

\section{Results from ERGMs and Metaregression: Who Rejects Whom?}

We now turn from predicting students' peer rejection scores and to instead the mechanisms shaping rejection ties between certain students, using ERGMs and metaregression to summarize the ERGM results across classrooms. Our formulated model converged for 175 out of the 201 classroom networks. In these networks, the convergence t-ratio was below 0.1 for all included parameters (Robins and Lusher 2013). Based on each fitted model, we simulate a distribution of networks and 
assessed goodness of fit by comparing the observed classroom network with characteristics of the distribution of networks predicted by our model. At this stage, $\mathrm{t}$-ratios for parameters included in our model should ideally not exceed 0.1, but some deviation is acceptable (Robins and Lusher 2013, 181). We exclude 18 networks where any parameter included in our model has a t-ratio of more than 0.2 (36 retained networks have t-ratios above 0.1 but not exceeding 0.2$).{ }^{4}$ We also assess goodness of fit against parameters not included in our model. ${ }^{5}$ Here the t-ratio should ideally not exceed 2, but again, some deviation is acceptable. We exclude 2 classroom networks with at least one parameter t-ratio above 3 (16 retained networks have t-ratios exceeding 2 but not exceeding 3 ). In all, 155 networks were used in the metaregression analyses. ${ }^{6}$

Table 4 presents results from the metaregression on the ERGM estimates. Our ERGM specification was the same for each classroom, but for classroom networks where a configuration did not exist, we excluded it for that classroom network (including non-existent configurations leads to model degeneracy). This leads to differences in the number of network parameters estimated in the metaregression. ${ }^{7}$

For the network structure variables, we find that reciprocity, where two students mutually rejected each other, was significantly more common than would be expected at random. Whereas two students rejecting the same other classmate was less common than expected at random (negative parameter for 2-in-star), we do see that more concentrated rejections where multiple students nominate the same classmate occurred more often in the networks than expected at random (positive and significant estimate for AinS). However, situations with multiple overlaps in which classmates chose to reject sets of students occurred to a lesser extent than expected at random (negative parameter for AT-D), so although students often rejected the same individual students, there is no indication that students ganged up on groups of peers (after controlling for individual student characteristics). Last, compared to at random, it was more likely that students received 
rejections without rejecting anyone themselves (sink), and less likely that they solely rejected others without receiving any rejections (source). The last two results are likely at least partly due to the fact that it was possible to nominate non-present classmates, whom in turn could not nominate anyone themselves.

We now turn to the role of sociodemographic characteristics in outgroup derogation. Hypothesis 2 states that different characteristic classmates would send more rejection nominations to each other than same characteristic classmates do. From Table 4, we observe several significant estimates for gender and immigration background. For gender we find significant sender, receiver, and interaction parameters, while for immigration background we find significant sender and significant interaction parameters. For household income we find a significant receiver parameter but not a significant sender parameter, nor any indication that students were more likely to reject those who were more dissimilar to themselves (as captured by the absolute difference parameter). For cognitive ability, we see that a higher cognitive test score was associated with a greater tendency to reject others, and a lower tendency to be rejected by others, but no evidence of a joint effect as a result of both the sender and the receiver's cognitive ability. No estimates are significant for parental education.

\section{[TABLE 4 ABOUT HERE]}

To facilitate the interpretation for gender and immigration background we calculate odds ratios using the sender, receiver, and interaction parameters (Robins and Daraganova, 2013, pp. 96-98). ${ }^{8}$ These are shown in Table 5. We observe a significantly higher tendency for gender outgroup derogation (girls reject boys, boys reject girls) than for ingroup derogation for both girls and boys. Furthermore, all combinations for gender are significantly different from the baseline (boy sending a rejection nomination to boy) at a 5\% level. However, girls rejecting boys was as 
likely as boys rejecting girls. For immigration background, we observe a significant tendency for outgroup derogation among Swedish origin students. Despite a trend for students of immigrant background to reject Swedish origin classmates more than immigrant background classmates, this difference did not reach significance. Furthermore, only Swedish origin-to-immigrant background significantly differs to the baseline (immigrant-to-immigrant). A student of immigrant background was substantially more likely to be rejected by a classmate of Swedish origin than immigrant background, whereas a Swedish origin student was equally likely to be rejected by a Swedish or immigrant background classmate. Yet overall, the findings for gender and immigrant background were largely consistent with Hypothesis 2.

[TABLE 5 ABOUT HERE]

Hypothesis 3 posited that the tendency to reject classmates on the basis of dissimilarity is stronger in classes where the prevalence of the different characteristic is lower. An indication of this can be seen from Table 4 , where the $\mathrm{I}^{2}$ (indicating to what extent parameter estimates vary across classrooms) is comparatively larger for gender and immigration background. Of course, a large $\mathrm{I}^{2}$ does not in itself indicate that the variation across classrooms correlates with the specific classroom characteristic as stated in Hypothesis 3, but simply that there is large variation in parameters across networks.

We therefore include classroom-level covariates on the right-hand side in the metaregressions. As shown in Table 6, few classroom-level characteristics significantly correlate with the ERGM coefficients. However, we do see significant estimates for immigration background, gender, and cognitive test score. As the share of girls in the classroom increased, so did both the likelihood of girls sending and receiving rejections (beyond effects of the gender distribution in the classroom) and the interaction estimate decreased (albeit not significantly). First, 
while this may seem at odds with findings from the multilevel-models, it should be kept in mind that multilevel-models do not control for network structure and that the estimates reflect the relative distribution of rejections. ${ }^{9}$ Table B2 in the Supplementary material shows that several network structure parameters vary systematically with the share of girls in the classroom, indicating that the underlying structure of rejections seems to differ across gender composition, but also that the baseline risk of a rejection being made did not change significantly. Second, the results from Table 6 describe variation in the average parameter estimates reported in Tables 4 and 5, which showed that outgroup derogation occurred both for boys and girls. When the share of girls in the classroom was higher, so was the relative estimates of rejection of girls by boys (receiver effect) and of boys by girls (sender effect), relative to boys rejecting boys. The smaller (in absolute sense) and nonsignificant estimate for homophily for girls further shows that girls' tendency to reject girls 'increased' faster than their tendency to reject boys as classroom composition skewed more towards girls. That is, girls' tendency towards outgroup derogation was smaller in classrooms with a higher share of girls, and boys' tendency was larger. So, for gender we did not find support for Hypothesis 3.

\section{[TABLE 6 ABOUT HERE]}

Tables 4 and 5 reported that on average, outgroup derogation occurred from Swedish students to classmates with immigrant background, but not vice versa. Table 6 shows that as the share of Swedish origin students in a classroom increased, the likelihood of Swedish origin students sending rejection nominations increased, whereas the interaction decreased. Swedish origin students increasingly rejected immigrant background classmates as the share of Swedish origin students increased. To a lesser and nonsignificant extent, immigrant students' outgroup derogation also increased in classes with a higher share of Swedish origin students. The large (in absolute sense) and significant estimate for the interaction (i.e., the increasing presence of rejection heterophily) 
among Swedish students generally lead to their outgroup derogation increasing as the share of Swedish students increases in a classroom. Thus, we find partial support for Hypothesis 3 according to immigration background.

Last, we find that as the average cognitive ability in the classroom increased, students with higher scores were less likely to be rejected by classmates (significant and negative estimate of receiver effect). Given that Table 4 showed a positive sender estimate for cognitive ability and a negative receiver estimate, this points towards some degree of increasing outgroup derogation for cognitive ability — as ability increased across classrooms, high ability students remained equally likely to reject peers but were increasingly less likely to be rejected by peers, thereby concentrating rejections among less able classmates. Thus, we find some support for Hypothesis 3 for cognitive ability.

\section{Discussion}

Peer rejection has substantial negative consequences for students' social life, mental well-being, and school adjustment (Arseneault, Bowes, and Shakoor 2010; Buhs, Ladd, and Herald 2006; Eriksen, Nielsen, and Simonsen 2014; Nakamoto and Schwartz 2010; Wolke and Lereya 2015). Although various sociodemographic characteristics are associated with peer relations at school, little is known about which characteristics have the strongest association with peer rejection, the social dynamics underlying rejection, or the extent to which associations and social dynamics are moderated by classroom contextual factors. In response to this dearth of knowledge, this study examined how sociodemographic characteristics at the student and classroom levels shape peer rejection, addressing the role of gender, immigration background, household income, and parental education. By applying both multilevel OLS regression and ERGMs, we showed how student characteristics and classroom composition both influence which students are rejected and the extent to which students reject classmates who are different to themselves. 
Our first research question addressed the moderating effect of classroom composition on being the target of peer rejection. We found that boys, students of immigrant background, as well as those with lower household income and lower cognitive ability were rejected by classmates to a greater extent than other students. While these findings were consistent with previous studies (Hjalmarsson 2018; Plenty and Jonsson 2017; Veenstra et al. 2010), the current findings also demonstrated that each of these not easily alterable characteristics were independently related to peer rejection. Furthermore, in line with Hypothesis 1, boys, girls, students of immigrant background, and students with lower cognitive ability, received a larger share of rejection nominations in classrooms where these characteristics were less common. Thus, our results confirmed that the group-context interactions suggested by person-group dissimilarity and power imbalance theories apply to these characteristics, which are each easily identifiable to peers in a classroom context. For immigrant background students, this finding is also consistent with reports that such students report greater loneliness and less peer acceptance in immigrant sparse school settings (Granvik Saminathen, Löfstedt, and Låftman 2020; Madsen et al. 2016). For gender and cognitive ability, we are, to the best of our knowledge, the first to demonstrate that person-group dissimilarity and power imbalance theories also extend to these characteristics.

Contrary to expectations, we observed that Swedish origin appeared most protective against rejection in absolute terms in classrooms with the least representation of same-characteristic peers (holding all else equal). Yet, if we considered distribution of rejection in relative terms, Swedish students did receive a higher share of the rejections sent in classrooms with a higher share of immigrant background students than in classrooms with a lower share. It should be kept in mind that in classes with a low share of Swedish origin students, there is typically a greater ethnic diversity, so Swedish origin students do not necessarily constitute a numerical minority in terms of 
ethnicity in such classes. Future research could extend the current research by better accounting for ethnicity among immigrant background students (see for instance Plenty and Jonsson 2017).

Despite suggestions that economically disadvantaged students may experience socioemotional difficulties in school contexts with few same-characteristic peers (Benner and Wang 2014; Crosnoe 2009), students with low household income received a similar number of rejection nominations across classrooms settings. If anything, household income was slightly more protective against rejection in low-income settings than in high-income settings. The similarity across income settings corresponded with a recent study finding that poor students also give and receive fewer friendship nominations at constant levels across classroom income composition (Author, submitted manuscript).

We did not find any indication of an association with parental education at the student or classroom-level. This is broadly consistent with the literature on socioeconomic background and bullying victimization, which reports weaker associations with parental education than with measures of affluence and wealth (Tippett and Wolke 2014). Instead, it was characteristics that are often either observable directly (gender and immigrant status) or indirectly via consumption indicators (household income) and performance in the classroom (cognitive ability) that played a role in shaping the individual rejection score.

Our second research question asked how classroom composition moderates the structure of peer rejections - that is, the likelihood of certain students rejecting certain classmates. Here, we examined the main effects of students' characteristics on outgroup derogation and then whether classroom-level characteristics moderated these associations. We found evidence of outgroup derogation on gender and among students of Swedish origin but not among students of immigrant background, nor on parental education, household income, or cognitive ability. Thus Hypothesis 2 
was partially supported, as for boys, girls, and students of immigrant background, rejection was more likely from different-characteristic peers than same-characteristic peers. For students of Swedish origin or with lower income, rejection was not more likely from students who are more dissimilar. For cognitive ability, higher ability students rejected others more and were themselves less likely to be rejected, but with no indication of outgroup derogation.

Thus, in terms of social identity theory (Tajfel 1982; Tajfel and Turner 1979), identities relating to social categories of gender and whether one belongs to the majority population related to the tendency to distance oneself from "outgroup" members. Importantly, this tendency does not simply reflect a preference to befriend same-characteristic classmates due to greater perceived similarities but represents an avoidance of different-characteristic classmates, which provides a challenge for building positive inter-group relationships. Schools' efforts to promote gender relations and the social integration of students of immigrant background could benefit by addressing these biases in students' interpersonal preferences. An additional challenge is that these biases are not necessarily conscious, they may be implicit (Dunham, Baron, and Banaji 2006) or potentially explained by other attributes that overlap with gender or immigration status, such as behavior, values, and interests (see Stark and Flache 2012).

Hypothesis 3 stated that outgroup derogation would be stronger in classes where the share of other-characteristic classmates was less prevalent. This hypothesis also received partial support. We found that Swedish origin students' outgroup derogation was stronger in classrooms with a higher share of Swedish origin students. On the other hand, immigrant background students were not increasingly likely to nominate students of Swedish origin in classrooms with a smaller share of Swedish origin students. For gender, we found the opposite relationship as expected from Hypothesis 3-outgroup derogation for a given gender decreased when that gender increasingly became the majority. No evidence for the classroom composition affecting outgroup derogation for 
income or parental education was found, but support was partly found for cognitive ability. Further, we found that the gender composition affected the overall structure of rejections in the classroomthat is, the social rules governing peer rejection appear to differ across classroom gender composition.

To our knowledge, this was the first study to examine outgroup derogation according to multiple characteristics, considering both the experience of being rejected as well as the act of rejecting, while examining classroom compositional effects. In doing so, the study builds on the recently emerging literature on negative ties, brings a contextual perspective to social network analysis, and provides a comprehensive picture of the social dynamics underlying peer rejection using a large, high quality dataset and applying a sophisticated social network methodology that accounts for endogenous network processes. Yet, neither our data nor our empirical strategies are without important limitations.

First and foremost, we studied 14-15 years old students living in Sweden. The age of the respondents may affect the findings, particularly those on gender outgroup derogation. Differences in adolescent development could account for the difference in patterns across gender. Future studies could aim to replicate this study in younger and older participants to clarify the extent to which gender outgroup derogation weakens or persists across the school years. Similarly, replication of findings in countries with different gender norms and immigration policies could further elucidate whether the patterns we have uncovered only differ across classroom contexts or if they might also differ across country contexts.

Secondly, our operationalization of immigration background was necessary for statistical efficiency. Results could vary according to generation (first or second), the timing of arrival, and region of origin. Other studies have better addressed the experience of single ethnic groups (e.g., 
Boda and Neray 2015). While we were unable to address this heterogeneity, future studies could consider subgroups within the immigrant background category to further unpack the individual roles of for example, migratory reasons, language and cultural background.

Lastly, considering, for example, that immigrant background students in Sweden often have low household income, future studies could look at cumulative effects of differing to classmates according to multiple characteristics. Benner and Wang (2014) found it was a combination of being

socioeconomically (measured as low parental education) and ethnically marginalized that predicted low school attachment, rather than parental education only (ethnic marginalization predicted low school attachment). The current study used administrative data derived measures of students' characteristics. However, given that social identity is central to one's perceptions of others and oneself, future research could also examine how differences between subjective identity and the perceived identity of classmates influence rejections.

\section{Conclusion}

We examined the role of multiple sociodemographic characteristics in peer rejection using high quality measures, a large, representative sample, and a sophisticated two-pronged empirical approach. In doing so, we provided a more comprehensive picture of inequalities in peer rejection than has previously been presented. In summary, our study shows that multiple sociodemographic characteristics that are publicly displayed, difficult to change, and visible are associated with peer rejection in the classroom. Furthermore, classroom composition moderates how these characteristics, particularly gender and immigration background, are associated with rejection. However, we find that specific patterns of rejection are complex and vary between different types of characteristics. 


\section{Endnotes}

${ }^{1}$ Students classified as of immigrant background thus includes students with both a first- and second-generation immigration background.

${ }^{2}$ Further, ICC estimates are biased upwards, so the true ICCs for gender and peer rejection are likely even closer to zero.

${ }^{3}$ We use PNet (Wang et al. 2009) to estimate ERGMs.

${ }^{4}$ Initially, 135 networks had included parameter estimates with t-ratios above 0.1 (76 of which also had t-ratios exceeding 0.2). Following Robins \& Lusher (2013) we ran a larger goodness of fit estimation (using 5000000 simulations per network taking a sample of 1000 networks) on these 135 networks.

${ }^{5}$ We assessed goodness of fit against statistics of graph counts (and associated statistics), degree distributions, clustering, and counts of triads, following the list recommended for directed networks by Robins, Pattison and Wang (2009) and Robins and Lusher (2013).

${ }^{6}$ Network models place high demand on the data used and having to discard 46 classrooms networks out of 201 is a substantial sample restriction. However, compared to other similar studies, we retain substantially higher number of networks and sample size (Boda and Neray 2015; Leszczensky and Pink 2019). To ensure internal consistency, we have rerun our MLM analysis using only the 155 classrooms included in the ERGM analysis. Results remain the same as can be seen from Table B1 in the Supplementary material.

${ }^{7}$ Since a number of classrooms had no students with an immigrant background or of Swedish origin (or included no such student sending, or receiving, or included no rejection nomination between students of the same characteristic), the $\mathrm{N}$ is substantially lower for the three parameters relating to immigration background. 
${ }^{8}$ Odds ratios are conditional on the surrounding network structure.

${ }^{9}$ Further, Table B2 shows no significant variation in the baseline risk of any rejection tie forming (the estimate for "Arc") across any of the classroom level variables. 


\section{References}

Arseneault, Louise., Lucy. Bowes, and Sania. Shakoor. 2010. "Bullying Victimization in Youths and Mental Health Problems: 'Much Ado about Nothing'?” Psychological Medicine 40 (5): 71729. https://doi.org/10.1017/S0033291709991383.

Benner, Aprile D., and Yijie Wang. 2014. "Demographic Marginalization, Social Integration, and Adolescents' Educational Success.” Journal of Youth and Adolescence 43 (10): 1611-27. https://doi.org/10.1007/s10964-014-0151-6.

Boda, Zsofia, and Balint Neray. 2015. "Inter-Ethnic Friendship and Negative Ties in Secondary School." Social Networks 43 (October): 57-72. https://doi.org/10.1016/j.socnet.2015.03.004.

Boele, Savannah, Jelle J. Sijtsema, Theo A. Klimstra, Jaap J. A. Denissen, and Wim H. J. Meeus. 2017. "Person-Group Dissimilarity in Personality and Peer Victimization." European Journal of Personality 31 (3): 220-33. https://doi.org/10.1002/per.2105.

Boivin, Michel., Kenneth. A. Dodge, and John. D. Coie. 1995. "Individual-Group Behavioral Similarity and Peer Status in Experimental Play Groups of Boys: The Social Misfit Revisited." Journal of Personality and Social Psychology 69 (2): 269-79. https://www.ncbi.nlm.nih.gov/pubmed/7643305.

Buhs, Eric S., Gary W. Ladd, and Sarah L. Herald. 2006. "Peer Exclusion and Victimization: Processes That Mediate the Relation Between Peer Group Rejection and Children's Classroom Engagement and Achievement?” Journal of Educational Psychology 98 (1): 1-13. https://doi.org/10.1037/0022-0663.98.1.1.

Chang, Lei. 2004. "The Role of Classroom Norms in Contextualizing the Relations of Children's Social Behaviors to Peer Acceptance." Developmental Psychology 40 (5): 691. http://psycnet.apa.org/journals/dev/40/5/691/.

Cillessen, Antonius H. N., and Peter E. L. Marks. 2011. "Conceptualizing and Measuring Popularity." In Popularity in the Peer System, edited by Antonius H. N. Cillessen, David Schwartz, and Lara Mayeux, 25-56. New York; London: Guilford Press.

CILS4EU. 2016. "Children of Immigrants Longitudinal Survey in Four European Countries. Technical Report. Wave 1-2010/2011, v1.2.0.” Mannheim: Mannheim University.

Crosnoe, Robert. 2009. "Low-Income Students and the Socioeconomic Composition of Public High Schools.” American Sociological Review 74 (5): 709-30. https://doi.org/10.1177/000312240907400502.

Dunham, Yarrow, Andrew Scott Baron, and Mahzarin R. Banaji. 2006. "From American City to Japanese Village: A Cross-Cultural Investigation of Implicit Race Attitudes." Child Development 77 (5): 1268-81. https://doi.org/10.1111/j.1467-8624.2006.00933.x. 
Eriksen, Tine Louise Mundbjerg, Helena Skyt Nielsen, and Marianne Simonsen. 2014. "Bullying in Elementary School." The Journal of Human Resources 49 (4): 839-71. https://doi.org/10.3368/jhr.49.4.839.

Gifford-Smith, Mary E., and Celia A. Brownell. 2003. "Childhood Peer Relationships: Social Acceptance, Friendships, and Peer Networks." Journal of School Psychology 41 (4): 235-84. https://doi.org/10.1016/S0022-4405(03)00048-7.

Graham, Sandra. 2006. "Peer Victimization in School: Exploring the Ethnic Context." Current Directions in Psychological Science 15 (6): 317-21. https://doi.org/10.1111/j.14678721.2006.00460.x.

Granvik Saminathen, M., P. Löfstedt, and S. B. Låftman. 2020. "Classroom Immigrant Density, Peer Acceptance and Psychological Complaints among Adolescents with an Immigration Background: Findings from the 2017/18 Swedish Health Behaviour in School-Aged Children Study." In Effective Schools in a Segregated Landscape: Studies of Academic Achievement and Psychological Well-Being among Adolescents in Sweden (Doctoral Dissertation), Granvik Saminathen. Stockholm: Stockholm University.

Harrigan, Nicholas, and Janice Yap. 2017. "Avoidance in Negative Ties: Inhibiting Closure, Reciprocity, and Homophily." Social Networks 48: 126-41. http://dx.doi.org/10.1016/j.socnet.2016.07.003.

Hjalmarsson, Simon. 2018. "Poor Kids? Economic Resources and Adverse Peer Relations in a Nationally Representative Sample of Swedish Adolescents." Journal of Youth and Adolescence 47 (1): 88-104. https://doi.org/10.1007/s10964-017-0747-8.

Hong, Jun Sung, and Dorothy L. Espelage. 2012. "A Review of Research on Bullying and Peer Victimization in School: An Ecological System Analysis." Aggression and Violent Behavior 17 (4): 311-22. https://doi.org/10.1016/j.avb.2012.03.003.

Huitsing, Gijs, Marijtje A. J. van Duijn, Tom A. B. Snijders, Peng Wang, Miia Sainio, Christina Salmivalli, and René Veenstra. 2012. "Univariate and Multivariate Models of Positive and Negative Networks: Liking, Disliking, and Bully-Victim Relationships.” Social Networks 34 (4): 645-57. https://doi.org/10.1016/j.socnet.2012.08.001.

Kalter, Frank, Anthony F. Heath, Miles Hewstone, J. O. Jonsson, Matthijs Kalmijn, Irena Kogan, and Frank Van Tubergen. 2014. "Children of Immigrants Longitudinal Survey in Four European Countries (CILS4EU).” Cologne, GESIS Data Archive. https://doi.org/ZA5353 Data File Version 1.1.0.

Knaappila, Noora, Mauri Marttunen, Sari Fröjd, Nina Lindberg, and Riittakerttu Kaltiala-Heino. 2018. "Socioeconomic Trends in School Bullying among Finnish Adolescents from 2000 to 2015." Child Abuse \& Neglect 86 (December): 100-108. https://doi.org/10.1016/j.chiabu.2018.09.011.

Leary, Mark R. 2015. "Emotional Responses to Interpersonal Rejection." Dialogues in Clinical Neuroscience 17 (4): 435-41. https://doi.org/10.31887/DCNS.2015.17.4/mleary. 
Leszczensky, Lars, and Sebastian Pink. 2019. "What Drives Ethnic Homophily? A Relational Approach on How Ethnic Identification Moderates Preferences for Same-Ethnic Friends." American Sociological Review 84 (3): 394-419. https://doi.org/10.1177/0003122419846849.

Lusher, Dean, and Garry Robins. 2013. "Personal Attitudes, Perceived Attitudes, and Social Structures: A Social Selection Model." In Exponential Random Graph Models for Social Networks: Theory, Methods and Applications., edited by Dean Lusher, Johan Koskinen, and Garry Robins. Cambridge: Cambridge University Press.

Madsen, Katrine Rich, Mogens Trab Damsgaard, Mark Rubin, Signe Smith Jervelund, Mathias Lasgaard, Sophie Walsh, Gonneke G. W. J. M. Stevens, and Bjørn E. Holstein. 2016. "Loneliness and Ethnic Composition of the School Class: A Nationally Random Sample of Adolescents." Journal of Youth and Adolescence 45 (7): 1350-65. https://doi.org/10.1007/s10964-016-0432-3.

Mikami, Amori Yee, Matthew D. Lerner, and Janetta Lun. 2010. "Social Context Influences on Children's Rejection by Their Peers." Child Development Perspectives 4 (2): 123-30. https://doi.org/10.1111/j.1750-8606.2010.00130.x.

Nakamoto, Jonathan, and David Schwartz. 2010. "Is Peer Victimization Associated with Academic Achievement? A Meta-Analytic Review." Social Development 19 (2): 221-42. https://doi.org/10.1111/j.1467-9507.2009.00539.x.

Neckerman, Holly J. 1996. "The Stability of Social Groups in Childhood and Adolescence: The Role of the Classroom Social Environment." Social Development 5 (2): 131-45. https://doi.org/10.1111/j.1467-9507.1996.tb00076.x.

Plenty, Stephanie, and Jan O. Jonsson. 2017. "Social Exclusion among Peers: The Role of Immigrant Status and Classroom Immigrant Density." Journal of Youth and Adolescence 46 (6): 127588. https://doi.org/10.1007/s10964-016-0564-5.

Robins, Garry, and Dean Lusher. 2013. "Illustrations: Simulation, Estimation, and Goodness of Fit." In Exponential Random Graph Models for Social Networks: Theory, Methods, and Applications, edited by Dean Lusher, Johan Koskinen, and Garry Robins. Cambridge University Press.

Robins, Garry, Pip Pattison, and Peng Wang. 2009. "Closure, Connectivity and Degree Distributions: Exponential Random Graph (P*) Models for Directed Social Networks.” Social Networks 31 (2): 105-17. https://doi.org/10.1016/j.socnet.2008.10.006.

Sentse, Miranda, Ron Scholte, Christina Salmivalli, and Marinus Voeten. 2007. "Person-Group Dissimilarity in Involvement in Bullying and Its Relation with Social Status." Journal of Abnormal Child Psychology 35 (6): 1009-19. https://doi.org/10.1007/s10802-007-9150-3.

Smith, Sanne, Frank Van Tubergen, Ineke Maas, and Daniel A. McFarland. 2016. "Ethnic Composition and Friendship Segregation: Differential Effects for Adolescent Natives and 
Immigrants." AJS; American Journal of Sociology 121 (4): 1223-72. https://doi.org/10.1086/684032.

Snijders, Tom. A. B., and Chris Baerveldt. 2003. "A Multilevel Network Study of the Effects of Delinquent Behavior on Friendship Evolution." The Journal of Mathematical Sociology 27 (2-3): 123-51. https://doi.org/10.1080/00222500305892.

Stark, Tobias H., and Andreas Flache. 2012. "The Double Edge of Common Interest: Ethnic Segregation as an Unintended Byproduct of Opinion Homophily." Sociology of Education 85 (2): 179-99. https://doi.org/10.1177/0038040711427314.

Stormshak, Elizabeth A., Karen L. Bierman, Carole Bruschi, Kenneth A. Dodge, and John D. Coie. 1999. "The Relation between Behavior Problems and Peer Preference in Different Classroom Contexts.” Child Development 70 (1): 169-82. https://doi.org/10.1111/1467-8624.00013.

Tajfel, Henri. 1982. "Social Psychology of Intergroup Relations.” Annual Review of Psychology 33 (1): 1-39. https://doi.org/10.1146/annurev.ps.33.020182.000245.

Tajfel, Henri, and John C. Turner. 1979. "An Integrative Theory of Intergroup Conflict." In The Social Psychology of Intergroup Relations, edited by William G. Austin and Stephen Worchel, 56:33-47. Belmont, CA: Brooks/Cole.

Tippett, Neil, and Dieter Wolke. 2014. "Socioeconomic Status and Bullying: A Meta-Analysis." American Journal of Public Health 104 (6): e48-59. https://doi.org/10.2105/AJPH.2014.301960.

Veenstra, René, Siegwart Lindenberg, Anke Munniksma, and Jan Kornelis Dijkstra. 2010. “The Complex Relation between Bullying, Victimization, Acceptance, and Rejection: Giving Special Attention to Status, Affection, and Sex Differences." Child Development 81 (2): 480 86. https://doi.org/10.1111/j.1467-8624.2009.01411.x.

Wang, Peng, Garry Robins, Philippa Pattison, and Johan Koskinen. 2009. PNet: Program for the Simulation and Estimation of Exponential Random Graph Models (version 1.0). Melbourne School of Psychological Sciences, The University of Melbourne.

Weiß, Rudolf H. 2006. CFT 20-R: Grundintelligenztest Skala 2-Revision. Göttingen: Hogrefe.

Wittek, Mark, Clemens Kroneberg, and Kathrin Lämmermann. 2020. "Who Is Fighting with Whom? How Ethnic Origin Shapes Friendship, Dislike, and Physical Violence Relations in German Secondary Schools." Social Networks 60 (January): 34-47. https://doi.org/10.1016/j.socnet.2019.04.004.

Wolke, Dieter, and Suzet Tanya Lereya. 2015. "Long-Term Effects of Bullying." Archives of Disease in Childhood 100 (9): 879-85. https://doi.org/10.1136/archdischild-2014-306667.

Wright, Jack. C., Mary. Giammarino, and Harry. W. Parad. 1986. "Social Status in Small Groups: Individual-Group Similarity and the Social "Misfit." Journal of Personality. http://psycnet.apa.org/journals/psp/50/3/523/. 


\section{Tables}

Table 1. Descriptives of explanatory variables

\begin{tabular}{llll}
\hline Individual level & Mean & Std & $\mathrm{N}$ \\
Rejection score (between [0;1]) & 0.100 & 0.134 & 4,215 \\
Gender (1 = Girl) & 0.507 & 0.500 & 4,215 \\
Immigration background (1 = Swedish origin) & 0.669 & 0.471 & 4,215 \\
Household income (in SEK 100,000) & 4.779 & 2.622 & 4,181 \\
Parental education (in years) & 12.726 & 2.698 & 4,166 \\
Cognitive test score & 17.712 & 4.850 & 4,037 \\
& & & \\
Classroom level & & & \\
Rejection score & 0.100 & 0.035 & 4,215 \\
Gender (1 = Girl) & 0.503 & 0.116 & 4,215 \\
Share of Swedish origin (1 = Swedish) & 0.666 & 0.290 & 4,215 \\
Mean household income (in SEK 100,000) & 4.750 & 1.269 & 4,215 \\
Mean parental education (in years) & 12.682 & 1.145 & 4,215 \\
Mean cognitive test score & 17.697 & 2.012 & 4,215 \\
\hline Note: Descriptives are unweighted. Rejection score mean is identical at the individual and \\
classroom level due to the with-in classroom standardization of the score.
\end{tabular}


Table 2. Intraclass correlations for rejection score and individual level explanatory variables

\begin{tabular}{llll}
\hline Variable & ICC & SE & $\mathrm{N}$ \\
\hline Rejection score & 0.020 & 0.006 & 4,215 \\
Gender & 0.015 & 0.007 & 4,215 \\
Immigration background & 0.354 & 0.029 & 4,215 \\
Household income & 0.210 & 0.022 & 4,181 \\
Parental education & 0.147 & 0.015 & 4,166 \\
Cognitive test score & 0.133 & 0.018 & 4,037 \\
\hline
\end{tabular}

Note: ICCs estimated by mixed command in Stata 
Table 3. Multilevel Random Intercepts Model Predicting Individual Peer Rejection Score using Individual and Classroom-level Characteristics $(\mathrm{N}=3,982)$

\begin{tabular}{|c|c|c|c|}
\hline & Model 1 & Model 2 & Model 3 \\
\hline \multicolumn{4}{|l|}{ Individual characteristics } \\
\hline Gender (Girl) & $\begin{array}{l}-0.017 * * \\
(0.006)\end{array}$ & $\begin{array}{l}-0.017 * * \\
(0.006)\end{array}$ & $\begin{array}{l}-0.018 * * \\
(0.005)\end{array}$ \\
\hline Immigration background (Swedish origin) & $\begin{array}{l}-0.016 * * \\
(0.006)\end{array}$ & $\begin{array}{l}-0.035^{* *} \\
(0.006)\end{array}$ & $\begin{array}{l}-0.036^{* *} \\
(0.007)\end{array}$ \\
\hline Household income (in 100000 SEK) & $\begin{array}{l}-0.004 * * \\
(0.001)\end{array}$ & $\begin{array}{l}-0.005 * * \\
(0.001)\end{array}$ & $\begin{array}{l}-0.005^{* *} \\
(0.001)\end{array}$ \\
\hline Parental education (in years) & $\begin{array}{l}-0.001 \\
(0.001)\end{array}$ & $\begin{array}{l}-0.002 * \\
(0.001)\end{array}$ & $\begin{array}{l}-0.002 * \\
(0.001)\end{array}$ \\
\hline Cognitive test score & $\begin{array}{l}-0.004 * * \\
(0.000)\end{array}$ & $\begin{array}{l}-0.004 * * \\
(0.001)\end{array}$ & $\begin{array}{l}-0.004 * * \\
(0.001)\end{array}$ \\
\hline \multicolumn{4}{|l|}{ Classroom characteristics } \\
\hline Share of girls & & $\begin{array}{l}0.012 \\
(0.022)\end{array}$ & $\begin{array}{l}0.091 * * \\
(0.035)\end{array}$ \\
\hline Share with Swedish origin & & $\begin{array}{l}0.062 * * \\
(0.013)\end{array}$ & $\begin{array}{l}0.083 * * \\
(0.019)\end{array}$ \\
\hline Mean household income & & $\begin{array}{l}0.004 \\
(0.003)\end{array}$ & $\begin{array}{l}0.003 \\
(0.003)\end{array}$ \\
\hline Mean years of parental education & & $\begin{array}{l}0.005 \\
(0.004)\end{array}$ & $\begin{array}{l}0.005 \\
(0.004)\end{array}$ \\
\hline Mean cognitive test score & & $\begin{array}{l}0.002 \\
(0.002)\end{array}$ & $\begin{array}{l}0.001 \\
(0.002)\end{array}$ \\
\hline \multicolumn{4}{|l|}{ Cross-level interactions } \\
\hline Gender*Share of girls & & & $\begin{array}{l}-0.143^{* *} \\
(0.044)\end{array}$ \\
\hline Immigration background*Swedish share & & & $\begin{array}{l}-0.038+ \\
(0.021)\end{array}$ \\
\hline Household income*Mean hh. inc & & & $\begin{array}{l}0.001+ \\
(0.000)\end{array}$ \\
\hline Parental education*mean yrs par. educ. & & & $\begin{array}{l}-0.000 \\
(0.001)\end{array}$ \\
\hline $\begin{array}{l}\text { Cognitive test score*Mean cognitive test } \\
\text { score }\end{array}$ & & & $\begin{array}{l}-0.001 * * \\
(0.000)\end{array}$ \\
\hline Constant & $\begin{array}{l}0.119 * * \\
(0.006)\end{array}$ & $\begin{array}{l}0.131 * * \\
(0.006)\end{array}$ & $\begin{array}{l}0.138 * * \\
(0.007)\end{array}$ \\
\hline
\end{tabular}

Note: $+\mathrm{p}<0.10, * \mathrm{p}<0.05, * * \mathrm{p}<0.01$ 
Table 4. ERGM estimates summarized across classrooms obtained using metaregression

\begin{tabular}{|c|c|c|c|c|}
\hline Parameter & Estimate & SE & $\mathrm{N}$ & $\mathrm{I}^{2}$ \\
\hline \multicolumn{5}{|l|}{ Gender } \\
\hline Girl Sender & $0.616^{* *}$ & 0.133 & 155 & 0.724 \\
\hline Girl Receiver & $0.521 * *$ & 0.168 & 153 & 0.780 \\
\hline Sender*Receiver & $-1.509 * *$ & 0.195 & 133 & 0.785 \\
\hline \multicolumn{5}{|l|}{ Immigration background } \\
\hline Swedish origin Sender & $1.016^{* *}$ & 0.331 & 134 & 0.869 \\
\hline Swedish origin Receiver & 0.463 & 0.310 & 134 & 0.873 \\
\hline Sender*Receiver & $-0.848^{*}$ & 0.365 & 121 & 0.901 \\
\hline \multicolumn{5}{|l|}{ Household income } \\
\hline Income Sender & -0.001 & 0.013 & 155 & 0.305 \\
\hline Income Receiver & $-0.033^{*}$ & 0.014 & 155 & 0.523 \\
\hline Absolute difference & 0.004 & 0.012 & 155 & 0.230 \\
\hline \multicolumn{5}{|l|}{ Parental education } \\
\hline Par. educ. Sender & 0.003 & 0.009 & 155 & 0.226 \\
\hline Par. educ. Receiver & -0.012 & 0.009 & 155 & 0.349 \\
\hline Absolute difference & -0.007 & 0.008 & 155 & 0.046 \\
\hline \multicolumn{5}{|l|}{ Cognitive test score } \\
\hline Cog. test Sender & $0.027 * *$ & 0.006 & 155 & 0.425 \\
\hline Cog. test Receiver & $-0.022 * *$ & 0.005 & 155 & 0.418 \\
\hline Absolute difference & -0.007 & 0.005 & 155 & 0.305 \\
\hline \multicolumn{5}{|l|}{ Network structure } \\
\hline Arc & $-4.995^{* *}$ & 0.667 & 155 & 0.943 \\
\hline Reciprocity & $0.724 * *$ & 0.077 & 130 & 0.000 \\
\hline 2-path & 0.001 & 0.012 & 155 & 0.261 \\
\hline 2-in-star & $0.156^{* *}$ & 0.022 & 155 & 0.790 \\
\hline Sink & $1.211 * *$ & 0.257 & 154 & 0.594 \\
\hline Source & $-1.571 * *$ & 0.354 & 155 & 0.839 \\
\hline Isolates & -0.140 & 0.454 & 132 & 0.869 \\
\hline AinS & $2.692 * *$ & 0.474 & 155 & 0.951 \\
\hline AoutS & $0.396 *$ & 0.152 & 155 & 0.637 \\
\hline AT-D & $-0.388 * *$ & 0.042 & 151 & 0.364 \\
\hline
\end{tabular}

Note: $+\mathrm{p}<0.10, * \mathrm{p}<0.05, * * \mathrm{p}<0.01$. AinS, AoutS, and AT-D all have decay parameter lambda set at 2.0 
Table 5. Odds ratios for rejection nominations

\begin{tabular}{lllll}
\hline Sender & Receiver & & \multicolumn{2}{l}{ Outgroup derogation: Wald tests } \\
\hline Gender & Boy (0) & Girl (1) & & \\
Boy (0) & 1 & 1.701 & boy-boy vs. boy-girl & $p<.05$ \\
Girl (1) & 1.684 & 0.633 & girl-boy vs. girl-girl & $p<.05$ \\
& & & & \\
Immigration & & & & \\
background & Immigrant (0) & Swedish (1) & & imm-imm vs. imm-Swed \\
Immigrant (0) & 1 & 1.589 & Swed -imm vs. Swed -Swed & $p<.05$ \\
Swedish (1) & 2.762 & 1.879 & &
\end{tabular}


Table 6. ERGM estimates summarized across classrooms obtained using metaregression with classroom level characteristics as covariates

\begin{tabular}{|c|c|c|c|c|c|c|}
\hline \multirow[b]{2}{*}{ Parameters } & \multicolumn{6}{|c|}{ Classroom characteristics } \\
\hline & $\begin{array}{l}\text { Share } \\
\text { of girls }\end{array}$ & $\begin{array}{l}\text { Share of Swedish } \\
\text { origin }\end{array}$ & Income (mean) & $\begin{array}{l}\text { Parental education } \\
\text { (mean) }\end{array}$ & Cognitive test (mean) & $\mathrm{N}$ \\
\hline \multicolumn{7}{|l|}{ Gender } \\
\hline Girl Sender & $3.492^{* *}(1.166)$ & & & & & 155 \\
\hline Girl Receiver & $3.382^{*}(1.466)$ & & & & & 153 \\
\hline Sender*Receiver & $-2.173(1.782)$ & & & & & 133 \\
\hline \multicolumn{7}{|c|}{ Immigration background } \\
\hline Swedish Sender & & $3.059^{*}(1.354)$ & & & & 134 \\
\hline Swedish Receiver & & $1.373(1.260)$ & & & & 134 \\
\hline Sender*Receiver & & $-3.750^{*}(1.840)$ & & & & 121 \\
\hline \multicolumn{7}{|l|}{ Household income } \\
\hline Income Sender & & & $-0.006(0.010)$ & & & 155 \\
\hline Income Receiver & & & $0.005(0.010)$ & & & 155 \\
\hline Absolute difference & & & $-0.006(0.008)$ & & & 155 \\
\hline \multicolumn{7}{|l|}{ Parental education } \\
\hline Par. educ. Sender & & & & $-0.001(0.008)$ & & 155 \\
\hline Par. educ. Receiver & & & & $-0.008(0.008)$ & & 155 \\
\hline Absolute difference & & & & $0.003(0.007)$ & & 155 \\
\hline \multicolumn{7}{|l|}{ Cognitive test score } \\
\hline Cog. test Sender & & & & & $0.001(0.003)$ & 155 \\
\hline Cog. test Receiver & & & & & $-0.006^{*}(0.003)$ & 155 \\
\hline Absolute difference & & & & & $-0.004(0.003)$ & 155 \\
\hline
\end{tabular}

Note: $+\mathrm{p}<0.10, * \mathrm{p}<0.05, * * \mathrm{p}<0.01 ;$ All classroom level variables were mean centered. 


\section{Figures}

Figure 1. The distribution of rejections in an average classroom of 21 students

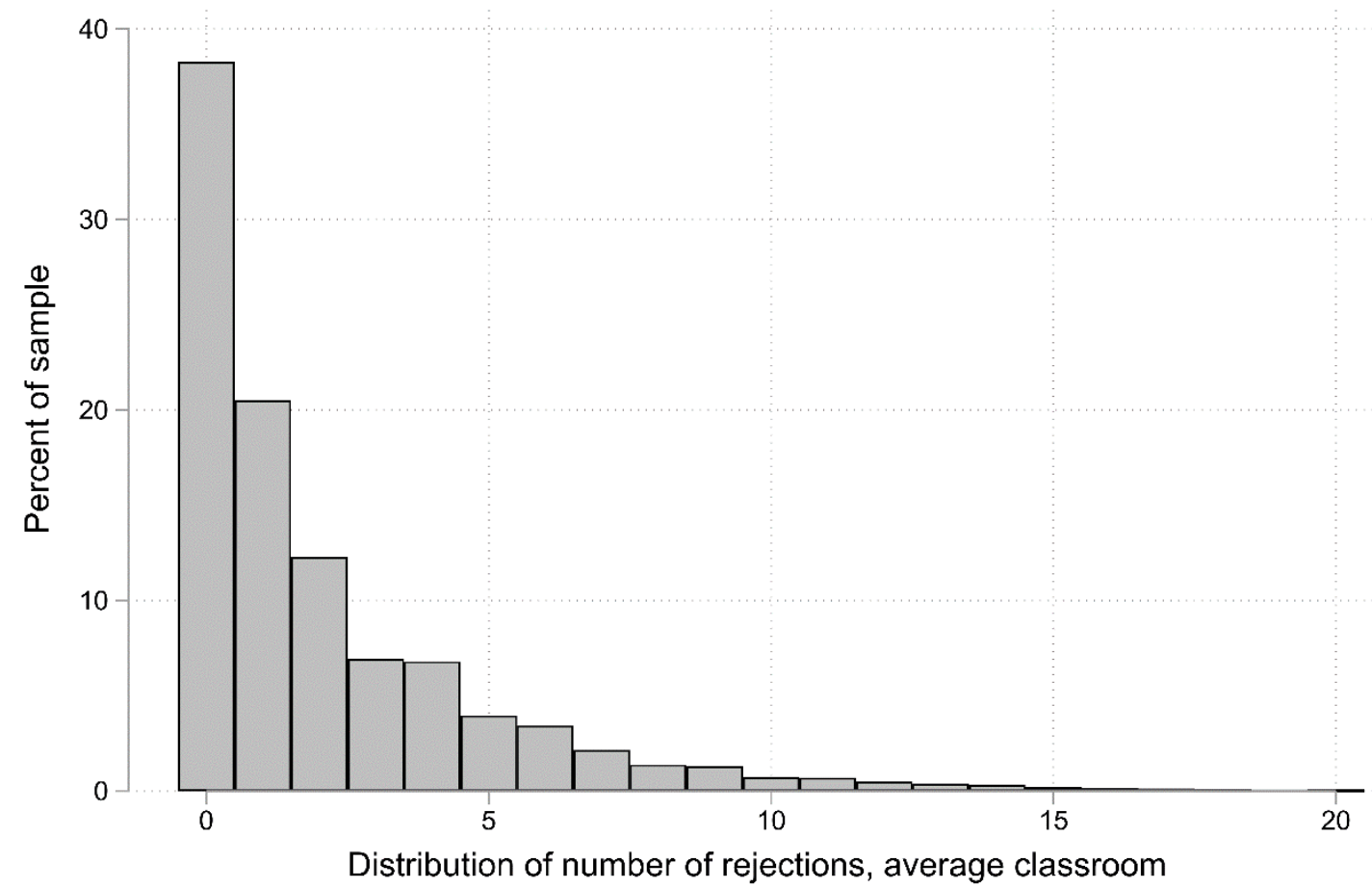


Figure 2. Linear predictions of rejection score for cross-level interactions

A

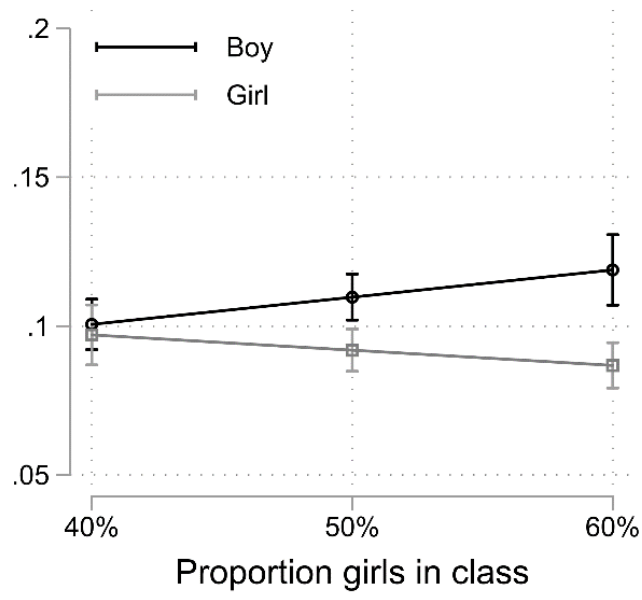

C

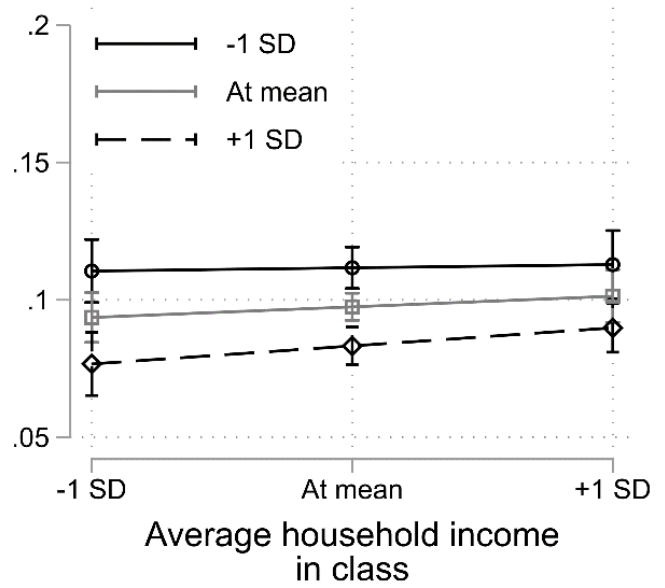

$E$

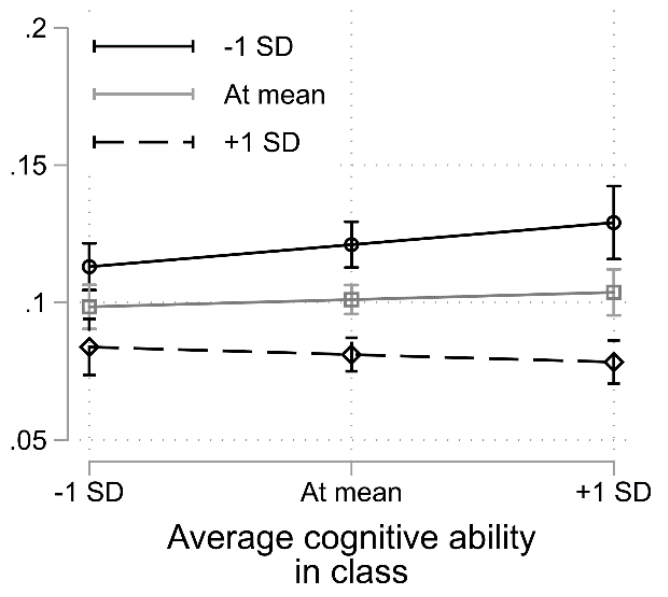

B

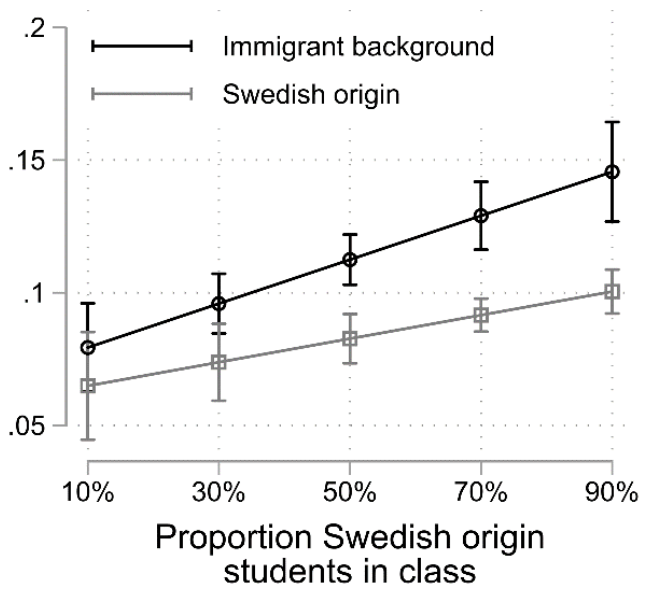

D

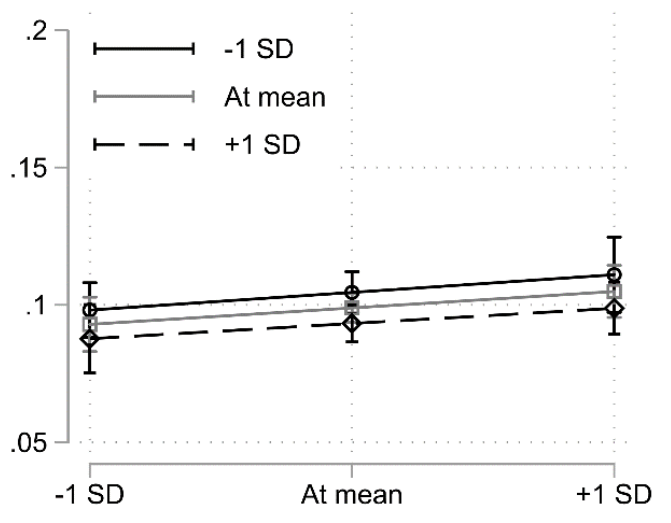

Average years of parental education in class 
Supplementary material for: Not Next to You: Peer Rejection, Student Characteristics and the Moderating Effects of Classroom Composition

\section{Appendix A: Overview of ERGM Specification}

Table A.1. Configurations modelled in ERGM

\begin{tabular}{ll}
\hline Actor attributes & Network structure attributes \\
\hline Gender & Arc \\
Girl Sender & Reciprocity \\
Girl Receiver & 2-path \\
Sender*Receiver & 2-in-star \\
& Sink \\
Immigration background & Source \\
Swedish Sender & Isolates \\
Swedish Receiver & AinS $(2.00)$ \\
Sender*Receiver & AoutS(2.00) \\
& AT-D $(2.00)$ \\
Household income & \\
Income Sender & \\
Income Receiver & \\
Absolute difference & \\
Parental education & \\
Par. educ. Sender & \\
Par. educ. Receiver & \\
Absolute difference & \\
Cognitive test score & \\
Cog. test Sender & \\
Cog. test Receiver & \\
Absolute difference &
\end{tabular}

\section{Description of Network Structure Attributes}

As the first structural parameter, we include a constant term capturing the propensity of rejection nominations in the network ( $\operatorname{arc})$, which is needed to examine if the baseline likelihood of the 
formation of rejection ties varies across classrooms. Second, we model reciprocity, which captures if students are more likely than at random to mutually nominate each other. ${ }^{1}$ We also include parameters that capture circuits connecting three students (i.e., 2-paths) and the case where two students nominate the same classmate (i.e., in-2-star). ${ }^{2}$

We also include a parameter to capture students who neither receive nor send rejection nominations (i.e., isolates), since negative networks tend to be much more sparse than positive networks. We also include a parameter capturing students who only receive but never send rejection nominations (i.e., sinks), and students who reject others but never receive rejections nominations (i.e., sources). Further, incoming rejection nominations are likely concentrated among some students who are more unpopular than others, so we also model this "inequality-in-nominations"effect for our classroom networks (i.e. alternating in-star). Similarly, as some students may reject more peers than others do, leading to a skewed distribution in outgoing nominations, we include a parameter to capture this spread in rejections nominations (i.e. alternating out-star). Finally, we found that more of our networks converged and model fit was improved when we included a structural homophily parameter that captures shared unpopularity (i.e., AT-D). We can think of the shared unpopularity parameter as capturing students' propensity to reject the same set of students that their other classroom peers reject (Robins, Pattison and Wang, 2009). ${ }^{3}$

\footnotetext{
${ }^{1}$ Reciprocity is a strong driver of positive ties (such as friendships), but whether this is the case also for negative ties (such as rejection) is more contested (see review in Harrigan and Yap, 2017).

${ }^{2}$ We do not include network statistics capturing transitivity (mechanisms of the type "a friend of a friend is more likely to be a friend"). Transitivity is an important driver of positive ties, but previous research has not found evidence of transitivity being a significant driver in the formation of negative ties (e.g., Harrigan and Yap, 2017; Lusher and Robins, 2013).

${ }^{3}$ For the alternating in-star (A-in-S), alternating out-star (A-out-S), and the shared unpopularity (AT-D) parameters we set the decay parameter (lambda) to equal 2.
} 
References, Appendix A

Harrigan, Nicholas, and Janice Yap. 2017. "Avoidance in Negative Ties: Inhibiting Closure, Reciprocity, and Homophily." Social Networks 48: 126-41. http://dx.doi.org/10.1016/j.socnet.2016.07.003.

Lusher, Dean, and Garry Robins. 2013. "Personal Attitudes, Perceived Attitudes, and Social Structures: A Social Selection Model.” In Exponential Random Graph Models for Social Networks: Theory, Methods and Applications., edited by Dean Lusher, Johan Koskinen, and Garry Robins. Cambridge: Cambridge University Press.

Robins, Garry, Pip Pattison, and Peng Wang. 2009. "Closure, Connectivity and Degree Distributions: Exponential Random Graph (P*) Models for Directed Social Networks.” Social Networks 31 (2): 105-17. https://doi.org/10.1016/j.socnet.2008.10.006. 


\section{Appendix B: Additional Tables and Figures}

Table B1. Multilevel Random Intercepts Model Predicting Individual Peer Rejection Score using Individual and Classroom-level Characteristics (sample restricted to same classrooms as in metaregression; $\mathrm{N}=3,045$ )

\begin{tabular}{|c|c|c|c|}
\hline & Model 1 & Model 2 & Model 3 \\
\hline \multicolumn{4}{|l|}{ Individual characteristics } \\
\hline Gender (Girl) & $\begin{array}{l}-0.021 * * \\
(0.006)\end{array}$ & $\begin{array}{l}-0.022 * * \\
(0.006)\end{array}$ & $\begin{array}{l}-0.022 * * \\
(0.006)\end{array}$ \\
\hline $\begin{array}{l}\text { Immigration background (Swedish } \\
\text { origin) }\end{array}$ & $\begin{array}{l}-0.022 * * \\
(0.007)\end{array}$ & $\begin{array}{l}-0.038 * * \\
(0.007)\end{array}$ & $\begin{array}{l}-0.039 * * \\
(0.008)\end{array}$ \\
\hline Household income (in 100000 SEK) & $\begin{array}{l}-0.003 * * \\
(0.001)\end{array}$ & $\begin{array}{l}-0.005 * * \\
(0.001)\end{array}$ & $\begin{array}{l}-0.005 * * \\
(0.001)\end{array}$ \\
\hline Parental education (in years) & $\begin{array}{l}-0.002+ \\
(0.001)\end{array}$ & $\begin{array}{l}-0.003 * * \\
(0.001)\end{array}$ & $\begin{array}{l}-0.003 * * \\
(0.001)\end{array}$ \\
\hline Cognitive test score & $\begin{array}{l}-0.004 * * \\
(0.001)\end{array}$ & $\begin{array}{l}-0.004 * * \\
(0.001)\end{array}$ & $\begin{array}{l}-0.004 * * \\
(0.001)\end{array}$ \\
\hline \multicolumn{4}{|l|}{ Classroom characteristics } \\
\hline Share of girls & & $\begin{array}{l}0.056 * \\
(0.024)\end{array}$ & $\begin{array}{l}0.138 * * \\
(0.038)\end{array}$ \\
\hline Share with Swedish origin & & $\begin{array}{l}0.065 * * \\
(0.016)\end{array}$ & $\begin{array}{l}0.080 * * \\
(0.022)\end{array}$ \\
\hline Mean household income & & $\begin{array}{l}0.003 \\
(0.004)\end{array}$ & $\begin{array}{l}0.003 \\
(0.004)\end{array}$ \\
\hline Mean years of parental education & & $\begin{array}{l}0.004 \\
(0.004)\end{array}$ & $\begin{array}{l}0.004 \\
(0.004)\end{array}$ \\
\hline Mean cognitive test score & & $\begin{array}{l}0.001 \\
(0.002)\end{array}$ & $\begin{array}{l}0.001 \\
(0.002)\end{array}$ \\
\hline \multicolumn{4}{|l|}{ Cross-level interactions } \\
\hline Gender*Share of girls & & & $\begin{array}{l}-0.146 * * \\
(0.049)\end{array}$ \\
\hline Immigration background $*$ Swedish share & & & $\begin{array}{l}-0.037 \\
(0.025)\end{array}$ \\
\hline Household income*Mean hh. inc & & & $\begin{array}{l}0.001 \\
(0.000)\end{array}$ \\
\hline Parental education*mean yrs par. educ. & & & $\begin{array}{l}-0.001 \\
(0.001)\end{array}$ \\
\hline $\begin{array}{l}\text { Cognitive test score* Mean cognitive test } \\
\text { score }\end{array}$ & & & $\begin{array}{l}-0.001 * \\
(0.000)\end{array}$ \\
\hline Constant & $\begin{array}{l}0.125 * * \\
(0.007)\end{array}$ & $\begin{array}{l}0.137 * * \\
(0.007)\end{array}$ & $\begin{array}{l}0.145^{* * *} \\
(0.008)\end{array}$ \\
\hline
\end{tabular}

Note: $+\mathrm{p}<0.10, * \mathrm{p}<0.05, * * \mathrm{p}<0.01$ 
Table B2: Variation in Estimates of Network Structure across Classroom Level Characteristics

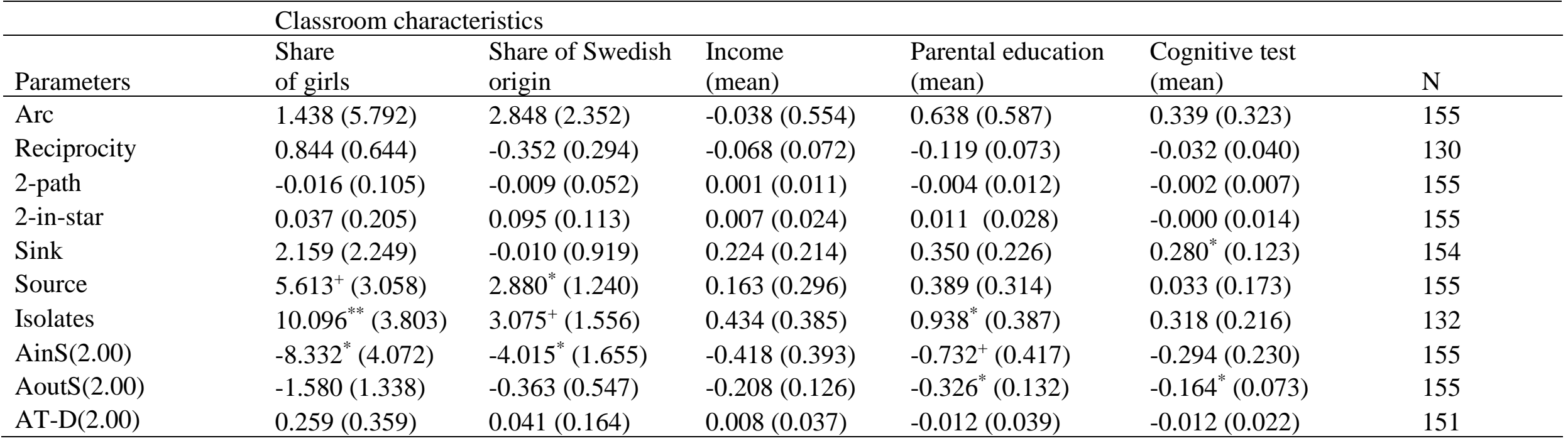

